\title{
Multicenter validation of the value of BASFI and BASDAI in Chinese ankylosing spondylitis and undifferentiated spondyloarthropathy patients
}

\author{
Zhiming Lin $\cdot$ Jieruo Gu $\cdot$ Peigen He $\cdot$ Jiesheng Gao $\cdot$ Xiaoxia Zuo \\ Zhizhong Ye $\cdot$ Fengmin Shao $\cdot$ Feng Zhan $\cdot$ Jinying Lin $\cdot \mathbf{L i ~ L i} \cdot$ \\ Yanlin Wei $\cdot$ Manlong Xu $\cdot$ Zetao Liao $\cdot$ Qu Lin
}

Received: 18 October 2009/Accepted: 29 November 2009/Published online: 13 December 2009

(C) The Author(s) 2009. This article is published with open access at Springerlink.com

\begin{abstract}
The objectives of this study were to evaluate the reliability of Bath ankylosing spondylitis functional index (BASFI) and Bath ankylosing spondylitis disease activity index (BASDAI) in Chinese ankylosing spondylitis (AS) and undifferentiated spondyloarthropathy (USpA) patients. 664 AS patients by the revised New York criteria for AS and 252 USpA patients by the European Spondyloarthropathy Study Group criteria were enrolled. BASDAI and BASFI questionnaires were translated into Chinese. Participants were required to fill in BASFI and BASDAI questionnaires again after $24 \mathrm{~h}$. Moreover, BASDAI and BASFI were compared in AS patients receiving Enbrel or infliximab before and after treatment. For AS group, BASDAI ICC: 0.9502 (95\% CI: $0.9330-0.9502, \alpha=0.9702)$, BASFI ICC: $0.9587(95 \%$ CI: $0.9521-0.9645, \alpha=0.9789)$. For USpA group, BASDAI ICC: 0.9530 (95\% CI: 0.9402-0.9632, $\alpha=0.9760$ ),
\end{abstract}

\footnotetext{
Z. Lin · J. Gu $(\bowtie) \cdot$ L. Li $\cdot$ Y. Wei $\cdot$ M. Xu $\cdot$ Z. Liao $\cdot$ Q. Lin Department of Rheumatology,

The Third Affiliated Hospital of Sun Yat-sen University,

Tianhe Road No 600, 510630 Guangzhou, China

e-mail: gujieruo@163.com; gujieruo@gmail.com

P. He

Department of Rheumatology, Tongji Hospital,

Tongji Medical College, Central China University

of Science and Technology, Hubei, China

J. Gao

Department of Rheumatology,

Xiangya Second Affiliated Hospital,

Central South University, Hunan, China
}

X. Zuo

Department of Rheumatology, Xiangya First Affiliated Hospital, Central South University, Hunan, China
BASFI ICC: $0.9900 \quad(95 \% \quad$ CI: $0.9871-0.9922$, $\alpha=0.9950)$. In the AS group, disease duration, occipital wall distance, modified Schober test, chest expansion, ESR, and CRP showed significant correlation with BASDAI and BASFI (all $P<0.01$ ). In the USpA group, onset age, ESR, and CRP were significantly correlated with BASDAI (all $P<0.05$ ), while modified Schober test, ESR, and CRP were significantly associated with BASFI (all $P<0.05$ ). The change in BASDAI and BASFI via Enbrel or infliximab treatment showed a significant positive correlation $(P<0.01)$. The two instruments have good reliability and reference value regarding the evaluation of patient's condition and anti-TNF- $\alpha$ treatment response.

Keywords Ankylosing spondylitis · BASDAI · BASFI - Reliability

Z. Ye

Shenzhen Rheumatology Institute of Guangdong Medical

College, Shenzhen, China

F. Shao

Department of Rheumatology, Henan Provincial People's

Hospital, Zhengzhou, China

F. Zhan

Department of Rheumatology, Hainan Provincial People's Hospital, Guangzhou, China

J. Lin

Department of Rheumatology, Guangxi Zhuangzu Autonomous

Region People's Hospital, Nanning, China 


\section{Introduction}

As a subtype of spondyloarthropathy (SpA), ankylosing spondylitis (AS) is a chronic inflammatory disorder of unknown etiology mainly affecting the spine and sacroiliac joints. The major clinical manifestations of AS include inflammatory back pain, morning stiffness, and limited spinal activity and/or concurrent peripheral arthritis and enthesitis and even spinal deformity or ankylosis at the advanced stage. Physical disability occurs in about one-third of AS patients within 15-20 years after the diagnosis [1]. There are many evaluation tools for AS, and the Bath ankylosing spondylitis functional index (BASFI) and disease activity index (BASDAI) are the most common tools used to assess patients suffering from AS. Other objective indicators include occipital wall distance, modified Schober test, chest expansion, and lateral flexion [2-5].

BASDAI and BASFI are often used to evaluate the USpA condition in some countries. However, it remains to be validated whether BASFI and BASDAI are also applicable in different countries and regions. Undifferentiated spondyloarthropathy (USpA) is the most common SpA subtype also characterized by inflammatory back pain and arthritis, and it does not conform to the criteria for AS, Reiter's syndrome, psoriatic arthritis or inflammatory bowel disease arthritis [6]. Here, we conducted this prospective, multi-center study to explore the reliability and reference value of BASDAI and BASFI in the evaluation of patient's condition and treatment response in China for the first time.

\section{Patients and methods}

\section{Patients}

The survey involved 664 AS patients and 252 USpA patients from eight centers (Department of Rheumatology, Third Affiliated Hospital of Sun Yat-sen University, Guangzhou; Department of Rheumatology, Tongji Hospital, Tongji Medical College, Central China University of Science and Technology, Hubei; Department of Rheumatology, Xiangya Second Affiliated Hospital, Central South University, Hunan; Department of Rheumatology, Xiangya First Affiliated Hospital, Central South University, Hunan; Shenzhen Rheumatology Institute of Guangdong Medical College; Department of Rheumatology, Henan Provincial People's Hospital; Department of Rheumatology, Hainan Provincial People's Hospital; Department of Rheumatology, Guangxi Zhuangzu Autonomous Region People's Hospital; China) over 6 years (2002-2007).
Questionnaires

Bath ankylosing spondylitis disease activity index (BASDAI): The index consists of six "10-cm" horizontal visual analog scales (VAS) to evaluate severity of fatigue, spinal and peripheral joint pain, localized tenderness, and morning stiffness [3]. A score of 0 means no symptoms, and a score of 10 means very severe symptoms. A mean score is calculated across all items. The range is from 0 to 10 .

Bath ankylosing spondylitis functional index (BASFI): Ten items are included concerning the respondents' perception of their functional ability and how well they are able to function in everyday life. $0-10 \mathrm{~cm}$ on a visual analog scale describes the current condition [2]. The mean score is calculated across all items (range 0-10).

\section{Translation}

The BASDAI and BASFI questionnaires were translated into Chinese by two independent bilingual physicians who were familiar with the medical aspects of AS and by one professional translator. Two rheumatologists familiar with instrument validation and aware of the purpose of the study examined semantic, idiomatic, and conceptual issues. English back-translation from the Chinese was done by a professional translator unaware of the original version. Both English versions were compared and necessary modifications to the Chinese versions were made to reach an agreement.

\section{Assessment}

First of all, the diagnosis was confirmed by an expert in rheumatology from each center according to the revised 1984 New York criteria for AS and European Spondyloarthropathy Study Group (ESSG) criteria for USpA; and then a full-time rheumatologist in the corresponding center conducted face-to-face interview. The survey includes demography, BASFI, BASDAI, spinal activity index (modified Schober's test, lateral flexion, occipital wall distance, and chest expansion) and laboratory indicator such as HLA-B27, erythrocyte sedimentation rate (ESR) and C-reactive protein (CRP), as well as sacroiliac joint $\mathrm{X}$-ray change (conducted within 2 months); $24 \mathrm{~h}$ after filling the form, without any drug treatment, the patients were retested using BASFI, BASDAI questionnaire, and the average score was used for further analysis. In addition, 39 active AS patients were administered Enbrel $(50 \mathrm{mg}$, subcutaneous injection, once a week) and 107 active AS patients received infliximab $(5 \mathrm{mg} / \mathrm{kg}$, venous injection, at weeks 0,2 , and 6) for a total of 6 weeks. After 6-week Enbrel or infliximab treatment, the BASDAI and BASFI were recorded and compared. By correlation analysis 
between BASFI and other parameters [5], we assessed the reliability and validity of BASFI and BASDAI in Chinese AS and USpA patients.

Statistical analysis

Data were expressed as mean \pm standard deviation ( $x \pm \mathrm{SD}, 95 \% \mathrm{CI}$ ). Intraclass correlation coefficient (ICC) for agreement (reliability) and consistency was calculated, and alpha statistic was calculated as an additional measure of reliability $(\alpha>0.75$ : very good test-retest reliability, 0.4-0.75: good test-retest reliability, $\alpha<0.4$ : poor testretest reliability). Validation was tested by calculation of Spearman's correlation coefficient $(r)$ between various parameters. $P<0.05$ was considered statistically significant. All data and statistical manipulation were processed using SPSS 12.0.

\section{Results}

Clinical data

AS patients (664): male:female $=6.9: 1$, average age: $30.0 \pm 9.3$ years, average onset age: $21.7 \pm 7.2$ years, average duration: $7.2 \pm 6.7$ years, family history: $18.4 \%$ $(n=122)$, HLA-B27 $(+)$ : $90.2 \%(n=599)$.

USpA patients (252): male:female $=2.0: 1$, average age: $26.0 \pm 9.3$ years, average onset age: $22.7 \pm 7.7$ years, average duration: $2.9 \pm 3.4$ years, family history: $19.8 \%$ $(n=50)$, HLA-B27 $(+): 67.9 \%(n=171)$.

\section{Reliability of BASDAI and BASFI}

Reliability showed an acceptable 24-h test-retest ICC. In the AS group, BASDAI ICC: 0.9502 (95\% CI: 0.93300.9502, $\alpha=0.9702)$, BASFI ICC: 0.9587 (95\% CI: 0.9521-0.9645, $\alpha=0.9789)$. In USpA group, BASDAI ICC: $0.9530 \quad(95 \% \quad \mathrm{CI}: 0.9402-0.9632, \alpha=0.9760)$, BASFI ICC: 0.9900 (95\% CI: 0.9871-0.9922, $\alpha=0.9950$ )

Correlation analysis between BASDAI, BASFI, and other clinical parameters

As shown in Table 1, in the AS group, the duration, occipital wall distance, modified Schober's test, ESR, and CRP were significantly associated with BASDAI and BASFI (all $P<0.01$ ), but we found no correlation between age at onset and BASDAI or BASFI. Table 2 showed that age at onset, ESR, and CRP were significantly associated with BASDAI (all $P<0.05$ ), and modified Schober's test,
Table 1 Correlation between BASDAI, BASFI, and other clinical parameters in AS

\begin{tabular}{|c|c|c|c|c|}
\hline & \multicolumn{2}{|c|}{ BASDAI } & \multicolumn{2}{|l|}{ BASFI } \\
\hline & $R$ & $P$ & $r$ & $P$ \\
\hline Age at onset (years) & 0.072 & 0.072 & 0.056 & 0.162 \\
\hline Duration (years) & 0.149 & 0.000 & 0.145 & 0.000 \\
\hline Occipital wall distance $(\mathrm{cm})$ & 0.159 & 0.000 & 0.308 & 0.000 \\
\hline Modified Schober's test (cm) & -0.214 & 0.000 & -0.308 & 0.000 \\
\hline Chest expansion $(\mathrm{cm})$ & -0.183 & 0.000 & -0.227 & 0.000 \\
\hline ESR $(\mathrm{mm} / \mathrm{h})$ & 0.263 & 0.000 & 0.295 & 0.000 \\
\hline CRP (mg/L) & 0.231 & 0.000 & 0.359 & 0.000 \\
\hline
\end{tabular}

$r$ Spearman's correlation coefficient

Table 2 Correlation between BASDAI, BASFI, and other clinical parameters in USpA

\begin{tabular}{|c|c|c|c|c|}
\hline & \multicolumn{2}{|c|}{ BASDAI } & \multicolumn{2}{|l|}{ BASFI } \\
\hline & $R$ & $P$ & $r$ & $P$ \\
\hline Age at onset (years) & 0.204 & 0.001 & -0.073 & 0.249 \\
\hline Duration (years) & 0.116 & 0.670 & 0.020 & 0.752 \\
\hline Modified Schober's test $(\mathrm{cm})$ & -0.109 & 0.860 & -0.314 & 0.000 \\
\hline Chest expansion $(\mathrm{cm})$ & 0.023 & 0.716 & 0.024 & 0.702 \\
\hline $\mathrm{ESR}(\mathrm{mm} / \mathrm{h})$ & 0.142 & 0.025 & 0.357 & 0.000 \\
\hline CRP (mg/L) & 0.211 & 0.001 & 0.336 & 0.000 \\
\hline
\end{tabular}

$r$ Spearman's correlation coefficient

ESR, and CRP were significantly correlated with BASFI (all $P<0.05)$.

\section{BASDAI and BASFI correlation}

The BASDAI and BASFI demonstrated significant positive correlation both in AS group (Fig. $1, r=0.587, P=0.000$ ) and in USpA group (Fig. 2, $r=0.590, P=0.000$ ).

BASDAI and BASFI changes via 6-week TNF- $\alpha$ antagonist treatment

We enrolled 39 active AS patients and kept record of their BASDAI $(4.92 \pm 1.75$ vs. $2.82 \pm 1.65)$ and BASFI $(3.99 \pm 2.34$ vs. $2.15 \pm 2.03)$ score at weeks 0 and 6 with Enbrel therapy. The changes between two index were statistically correlated (Fig. 3, $r=0.778, P=0.000$ ). In addition, we analyzed the change of BASDAI $(4.31 \pm 1.6$ vs. $0.96 \pm 1.1)$ and BASFI $(2.40 \pm 2.26$ vs. $0.67 \pm 1.11)$ in 107 USpA patients receiving infliximab for 6 weeks, and results showed that BASDAI and BASFI also improved, and their changes after treatment showed a weak positive correlation $(r=0.345, P=0.000)$. 


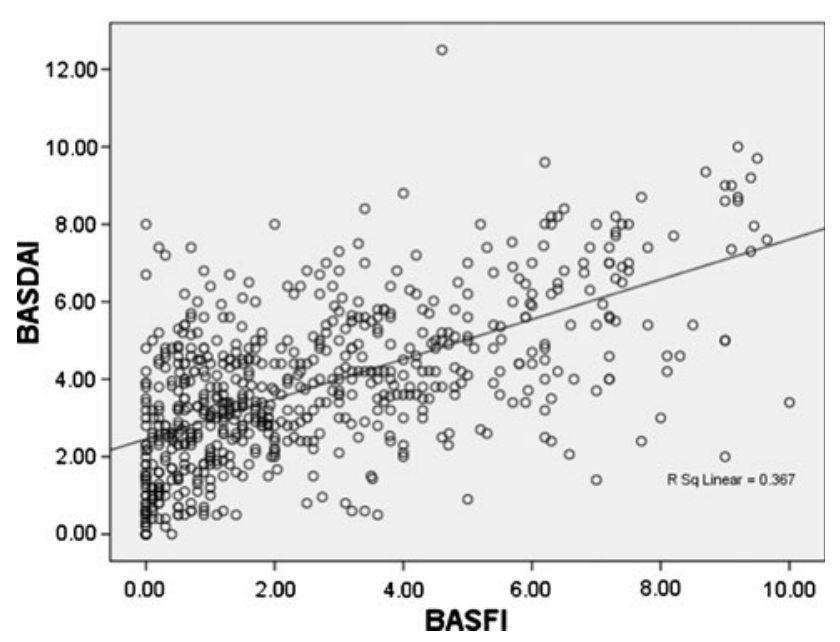

Fig. 1 The correlation between BASDAI and BASFI in AS

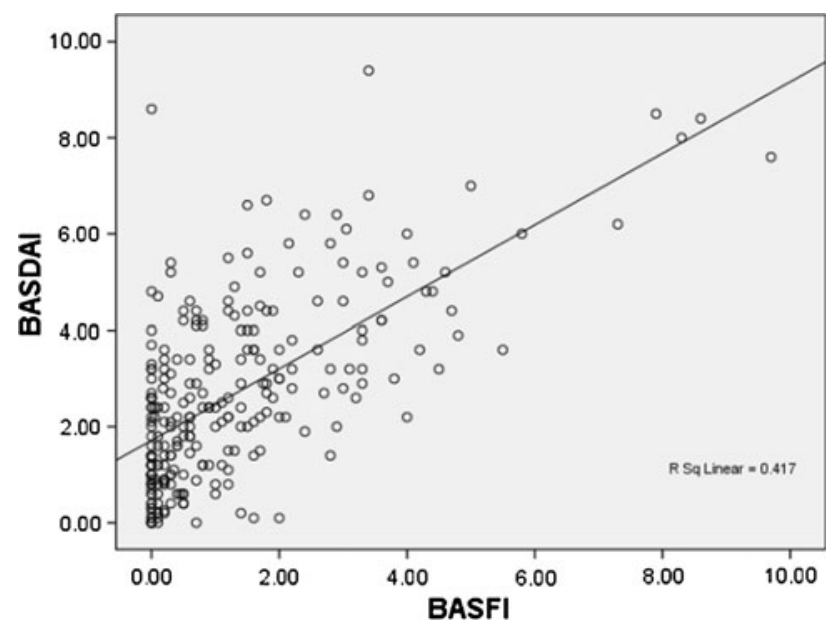

Fig. 2 The correlation between BASDAI and BASFI in USpA

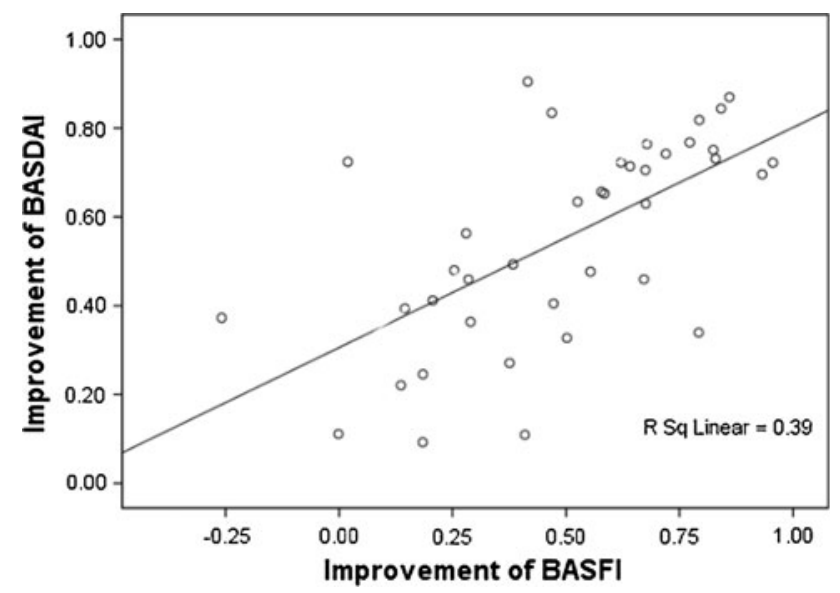

Fig. 3 The correlation improvement between BASDAI and BASFI with 6-week Enbrel therapy

\section{Discussion}

BASFI and BASDAI are two important tools used to assess the impact of AS on the quality of life dimensions of a patients with AS. In terms of the worldwide distribution of AS and the need for unified disease activity and functional indexes, those tools have to be adapted to different nations. The study aimed at assessing validity and reliability of the cross-culturally adapted versions of the BASFI and BASDAI.

BASDAI and BASFI questionnaires are widely used to evaluate disease activity and physical function, respectively, in patients with AS, and both are often applied in medical and clinical researches. The reliability of both questionnaires in evaluating AS has been validated by studies in some countries [7-11]. However, the validity of BASDAI and BASFI in patients with USpA was seldom investigated except that Cardiel et al. [9] mentioned it in a study involving 61 AS and 80 USpA patients in 2003. Additionally, in China, the reliability of these two instruments is still unclear, although they have been used in clinical and medical research for many years. In this study, the data coming from multi centers are representatives of the population. Results suggested that test-retest ICC for BASDAI and BASFI in patients with AS and USpA were similar to that in previous studies [7-11]; $\alpha>0.75$ in Chinese AS and USpA groups indicated that the two instruments have very good reliability and are well worth promoting.

In this study, we analyzed the correlation between BASDAI, BASFI and other clinical parameters using Spearman's correlation coefficient $(r)$. In the AS group (Table 1), the disease duration, occipital wall distance, modified Schober's test, chest expansion, ESR, and CRP were significantly associated with BASDAI and BASFI, but we found no correlation between age at onset and BASDAI or BASFI. In the USpA group (Table 2), the age at onset, ESR, and CRP were significantly associated with BASDAI, and modified Schober's test, ESR, and CRP were significantly correlated with BASFI.

As for the BASDAI, our results suggest that: (1) In both AS group and USpA group, CRP and ESR were significantly related to BASDAI, indicating that BASDAI could reflect the disease activity of both USpA and AS patients, consistent with a number of previous studies [7, 12, 13]. (2) In AS patients, the disease duration also showed a positive correlation with BASDAI, while USpA patients did not. This may be due to a longer course of disease in patients with AS, and some patients suffer even more than 10 years, and have axial involvement, with more sites also involved, leading to the increased BASDAI scores indicating inflammatory activity. While USpA patients tend to have a shorter duration, often less than 2 years, and not many 
patients have axial involvement, and fewer sites were involved, that is to say, early in the course of disease, patient's symptoms are relatively slight or concealed. Therefore, in such a short course of disease, the patient's inflammation indicators such as BASDAI scores did not change significantly. (3) In the AS group, modified Schober test is also significantly associated with the BASDAI but not in USpA group. This may be because USpA patients have shorter disease duration and no involvement of the lumbar spine in general. (4) In USpA group, onset age is also significantly associated with the BASDAI, which may be due to the earlier age of onset paralleling the more obvious and severe symptoms, especially peripheral symptoms, resulting in higher BASDAI; while for AS, the impact of onset age on inflammation is quite eclipsed by longer disease duration and more sites involved.

The results for the BASFI show that: (1) Most indicators such as modified Schober test do not suit USpA patients, since the vast majority of functions in those patients are normal. But the correlation between BASFI for patients with AS and the disease duration, occipital wall distance, modified Schober's test, and chest expansion, showing that limited physical function of patients is also aggravating with the longer duration. (2) For both AS and USpA group, ESR and CRP show significant correlation with BASFI, suggesting that the inflammatory activity affects the motor function partly.

All the above demonstrates that there is positive correlation between BASDAI and BASFI. This indicates that active inflammation has impact on physical function.

Last but not least, we also investigated the change in BASDAI and BASFI score in the treatment of drug responsiveness. Enbrel and Infliximab are commonly used anti-TNF- $\alpha$ biological agents in the treatment of AS, and its remarkable effectiveness has been widely confirmed [14-20]. In this study, results showed that BASDAI and BASFI in AS patients decreased significantly after Enbrel or infliximab treatment, and results suggest that after treatment, with the reduction of disease activity, physical function also improved. Decreased value in BASDAI and BASFI score also showed a clear correlation, indicating that these two questionnaires could act as good evaluation tools for therapeutic effect of Enbrel and infliximab.

In conclusion, results of this study revealed that the Chinese version of the questionnaires maintained all the properties of the original English-language forms of the instruments. The Chinese version of BASDAI and BASFI were found to be valid, reliable; hence, these instruments can be applied in the evaluation of patient's condition and anti-TNF treatment response.

Open Access This article is distributed under the terms of the Creative Commons Attribution Noncommercial License which permits any noncommercial use, distribution, and reproduction in any medium, provided the original author(s) and source are credited.

\section{References}

1. Boonen A, Chorus A, Midema H, van der Heijde D, van der Tempel H, van der Linden S (2001) Employment, work disability and work days lost in patients with ankylosing spondylitis: a cross sectional study of Dutch patients. Ann Rheum Dis 60:353-358

2. Calin A, Garrel S, Whitelock H, Kennedy LG, O'Hea J, Mallorie P et al (1994) A new approach to defining functional ability in ankylosing spondylitis: the development of the Bath ankylosing spondylitis functional index. J Rheumatol 21:2281-2285

3. Garret S, Ienkinson T, Kennedy G, Whitelock H, Gaisford P, Calin A (1994) A new approach to defining disease status in ankylosing spondylitis: the Bath ankylosing spondylitis disease activity index. J Rheumatol 21:2286-2291

4. Van der Heijde D, Dougados M, Davis J, Weisman M, Maksymowych W, Braun J et al (2005) Assessment in Ankylosing Spondylitis International Working Group/Spondylitis Association of America recommendation for conducting clinical trials in ankylosing spondylitis. Arthritis Rheum 52:386-394

5. Van der Heijde D, Calin A, Dougados M, Khan MA, van der Linden S et al (1999) Selection of instruments in the core set for DC-ART, SMARD, physical therapy and clinical record keeping in ankylosing spondylitis: progress report of the ASAS Working Group. J Rheumatol 26:951-954

6. Dougados M, van der Linden S, Juhlin R, Huitfeldt B, Amor B, Calin A et al (1991) The European Spondyloarthropathy Study Group preliminary criteria for the classification spondyloarthropathy. Arthritis Rheum 34:1218-1227

7. Spoorenberg A, van der Heijde D, de Klerk E, Dougados M, de Vlam K, Mielants H et al (1999) A comparative study of the usefulness of the Bath ankylosing spondylitis functional index and the Dougados functional index in the assessment of ankylosing spondylitis. J Rheumatol 26:961-965

8. Heikkilä S, Viitanen JV, Kautianen H, Kauppi M (2000) Evaluation of the Finnish versions of the functional indices BASFI and DFI in spondylarthropathy. Clin Rheumatol 19:464-469

9. Cardiel MH, Londoño JD, Gutiérrez E, Pacheco-Tena C, Vázquez-Mellado J, Burgos-Vargas R (2003) Translation, crosscultural adaptation, and validation of the Bath ankylosing spondylitis functional index (BASFI), the Bath ankylosing spondylitis disease activity index (BASDAI) and the Dougados functional index (DFI) in a Spanish speaking population with spondyloarthropathies. Clin Exp Rheumatol 21:451-458

10. Salaffi F, Stancati A, Silvestri A, Carotti M, Grassi W (2005) Validation of the Italian versions of the Bath ankylosing spondylitis functional index (BASFI) and the Dougados functional index (DFI) in patients with ankylosing spondylitis. Reumatismo 57:161-173

11. El Miedany Y, Youssef S, Mehanna A, Shebrya N, Abu Gamra S, El Gaafary M (2008) Defining disease status in ankylosing spondylitis: validation and cross-cultural adaptation of the Arabic Bath ankylosing spondylitis functional index (BASFI), the Bath ankylosing spondylitis disease activity index (BASDAI) and the Bath ankylosing spondylitis global score (BASG). Clin Rheumatol 27:605-612

12. Claudepierre P, Sibila J, Goupille P, Flipo RM, Wendling D, Eulry F et al (1997) Evaluation of a French version of the Bath ankylosing spondylitis disease activity index in patients with spondylarthropathy. J Rheumatol 24:1954-1958 
13. Keikkila S, Vitanen JV, Kautiainen H, Kauppi M (2002) Functional long term changes in patients with spondyloarthropathy. Clin Rheumatol 21:119-122

14. Brandt J, Khariouzov A, Listing J, Haibel H, Sörensen H, Grassnickel L et al (2003) Six-month results of a double-blind, placebo-controlled trial of etanercept treatment in patients with active ankylosing spondylitis. Arthritis Rheum 48:1667-1675

15. Brandt J, Listing J, Haibel H, Sörensen H, Schwebig A, Rudwaleit $\mathrm{M}$ et al (2005) Long-term efficacy and safety of etanercept after readministration in patients with active ankylosing spondylitis. Rheumatology 44:342-348

16. Davis JC, Van Der Heijde D, Braun J, Dougados M, Cush J, Clegg DO et al (2003) Recombinant human tumor necrosis factor receptor (etanercept) for treating ankylosing spondylitis: a randomized, controlled trial. Arthritis Rheum 48:3230-3236

17. Calin A, Dijkmans BA, Emery P, Hakala M, Kalden J, LeirisaloRepo $M$ et al (2004) Outcomes of a multicentre randomised clinical trial of etanercept to treat ankylosing spondylitis. Ann Rheum Dis 63:1594-1600

18. Braun J, Baraliakos X, Brandt J, Listing J, Zink A, Alten R et al (2005) Persistent clinical response to the anti-TNF-alpha antibody infliximab in patients with ankylosing spondylitis over 3 years. Rheumatology 44:670-676

19. van der Heijde D, Dijkmans B, Geusens P, Sieper J, DeWoody K, Williamson P et al (2005) Ankylosing spondylitis study for the evaluation of Recombinant Infliximab Therapy Study Group. Efficacy and safety of infliximab in patients with ankylosing spondylitis: results of a randomized, placebo-controlled trial (ASSERT). Arthritis Rheum 52:582-591

20. Gossec L, Le Henanff A, Breban M, Vignon E, Claudepierre P, Devauchelle V et al (2006) Continuation of treatment with infliximab in ankylosing spondylitis: 2-yr open follow-up. Rheumatology 45:859-862 